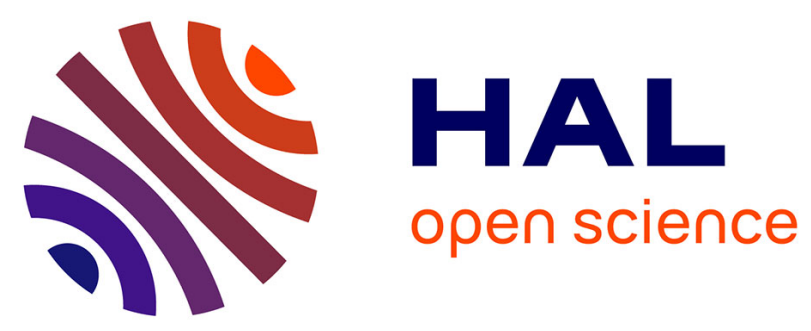

\title{
Microstructure investigation and flow behavior during thixoextrusion of M2 steel grade
}

\author{
Guochao Gu, Raphaël Pesci, Laurent Langlois, Eric Becker, Régis Bigot
}

\section{To cite this version:}

Guochao Gu, Raphaël Pesci, Laurent Langlois, Eric Becker, Régis Bigot. Microstructure investigation and flow behavior during thixoextrusion of M2 steel grade. Journal of Materials Processing Technology, 2015, 216, pp.178-187. 10.1016/j.jmatprotec.2014.09.009 . hal-01090603

\section{HAL Id: hal-01090603 https://hal.science/hal-01090603}

Submitted on 3 Dec 2014

HAL is a multi-disciplinary open access archive for the deposit and dissemination of scientific research documents, whether they are published or not. The documents may come from teaching and research institutions in France or abroad, or from public or private research centers.
L'archive ouverte pluridisciplinaire HAL, est destinée au dépôt et à la diffusion de documents scientifiques de niveau recherche, publiés ou non, émanant des établissements d'enseignement et de recherche français ou étrangers, des laboratoires publics ou privés. 


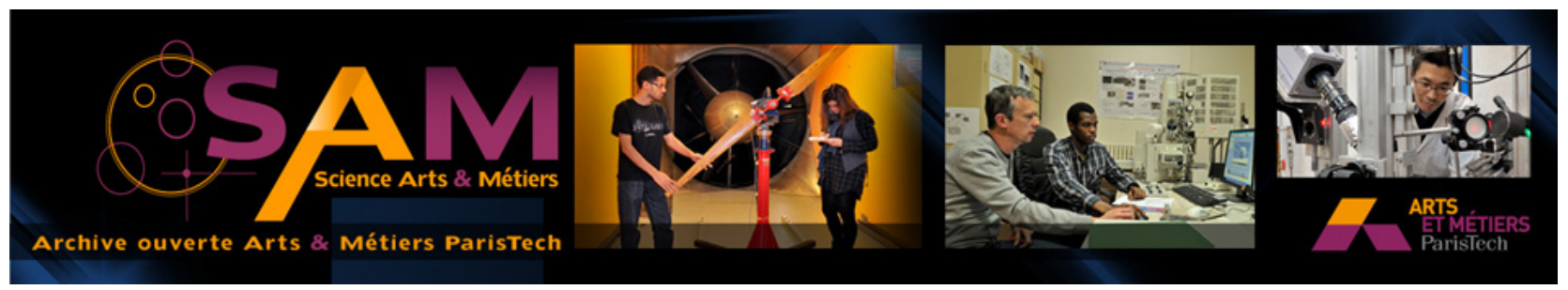

\section{Science Arts \& Métiers (SAM)}

is an open access repository that collects the work of Arts et Métiers ParisTech researchers and makes it freely available over the web where possible.

This is an author-deposited version published in: http://sam.ensam.eu

Handle ID: .http://hdl.handle.net/10985/9049

\section{To cite this version :}

Guochao GU, Raphaël PESCI, Laurent LANGLOIS, Eric BECKER, Régis BIGOT - Microstructure investigation and flow behavior during thixoextrusion of M2 steel grade - Journal of Materials Processing Technology - Vol. 216, p.178-187 - 2015 


\title{
Microstructure investigation and flow behavior during thixoextrusion of M2 steel grade
}

\author{
Guochao $\mathrm{Gu}^{\mathrm{a}, *}$, Raphaël Pesci ${ }^{\mathrm{b}}$, Laurent Langlois ${ }^{\mathrm{a}}$, Eric Becker ${ }^{\mathrm{a}}$, Régis Bigot ${ }^{\mathrm{a}}$ \\ a Laboratoire de Conception Fabrication Commande (LCFC-EA 4495), Arts et Métiers ParisTech CER Metz, 4 rue Augustin Fresnel, 57078 Metz Cedex 3, France \\ b Laboratoire d'Etude des Microstructures et de Mécanique des Matériaux (LEM3), UMR CNRS 7239, Arts et Métiers ParisTech CER Metz, \\ 4 rue Augustin Fresnel, 57078 Metz Cedex 3, France
}

\begin{abstract}
A B S T R A C T
The microstructure investigation and flow behavior during thixoforging of M2 steel parts were investigated. Partial remelting was performed at processing temperatures ranging from $1290^{\circ} \mathrm{C}$ to $1340^{\circ} \mathrm{C}$ corresponding to a liquid fraction range between 10\% and 30\% (according to differential scanning calorimetry measurements and quantitative image analyses). A conventional microstructure for thixoforming process was obtained: spherical solid grains surrounded by liquid phase. The microstructure across the heated billets was relatively homogeneous with bigger grain size near the surface. Successful thixoextrusion for producing parts was finally achieved at processing temperatures. By investigating the microstructure and load-displacement curves, different mechanisms in various forming stages were proposed.
\end{abstract}

\section{Introduction}

Thixoextrusion is a semi-solid forming process in which some metal parts are extruded in the semi-solid state taking advantage of the thixotropic properties of metals (Kirkwood et al., 1992). Prior to extrusion, the microstructure in the semi-solid state should present spheroids of solid surrounded by liquid in order to obtain the best thixotropic behavior in which viscosity decreases with increasing shear rate and increasing time at constant shear rate. The feedstock with the appropriate microstructures necessary for thixoforming can be obtained by several routes based either on liquid state (Legoretta et al., 2008) or on solid state (Kapranos et al., 1993). Originally, a semi-solid slurry with a globular microstructure was prepared by mechanical stirring during cooling a fully liquid alloy to the semi-solid state. Other more suitable routes for semi-solid alloy feedstock have been developed, including cooling slope (Haga and Suzuki, 2001), electromagnetic stirring (MHD) (Kenney et al., 1988), new rheocasting route (NRC) (Mitsure et al., 1996), shearing cooling rolling (SCR) (Kiuchi and Sugiyama, 1995), passive stirring (Moschini, 1992) etc. Spray forming has been

\footnotetext{
* Corresponding author. Tel.: +33 03873754 30; fax: +33 0387375470. E-mail addresses: guochao.gu@gmail.com (G.Gu),raphael.pesci@ensam.eu (R. Pesci), laurent.langlois@ensam.eu (L. Langlois), eric.becker@ensam.eu (E. Becker), regis.bigot@ensam.eu (R. Bigot).
}

studied for producing the materials (e.g. Al-Si (Hogg et al., 2004) and M2 (Dutkiewicz et al., 2010)) subjected to the semi-solid forming process. The materials present good globular microstructure. In addition, this method enables to eliminate band segregation of microstructure as compared to those produced by rolling or extruding routes. There are mainly two established solid state routes: the RAP (Recrystallization And Partial melting) (Kirkwood et al., 1992) and SIMA (Strain-Induced Melt Activation) (Yong et al., 1982). In both routes, the material is worked and recrystallization occurs during heating to the semi-solid state. The spherical solid grains surrounded by liquid can be obtained by liquid penetration on the recrystallized boundaries. The RAP route involves some cold or hot working below the recrystallization temperature, while SIMA involves hot working between the recrystallization and solidus temperatures. Various researchers have demonstrated that some metals can be subjected to a direct partial melting route from their as-received state (without any special treatment) in order to obtain a thixoformable microstructure (e.g. 7075 aluminum alloys (Chayong et al., 2005), 100Cr6 (Bulte and Bleck, 2004), M2 (Omar et al., 2009) and HP9/4/30 (Omar et al., 2005)).

Up to now, this technology has been industrialized in low melting alloys, such as aluminum and magnesium-based alloys (Kirkwood et al., 2010), while some obstacles (e.g. tool materials (Rassili et al., 2004), temperature controlling (Becker et al., 2010a)) need to be overcome for the application of this technique to high melting alloys such as steels. Therefore, this technique has been 


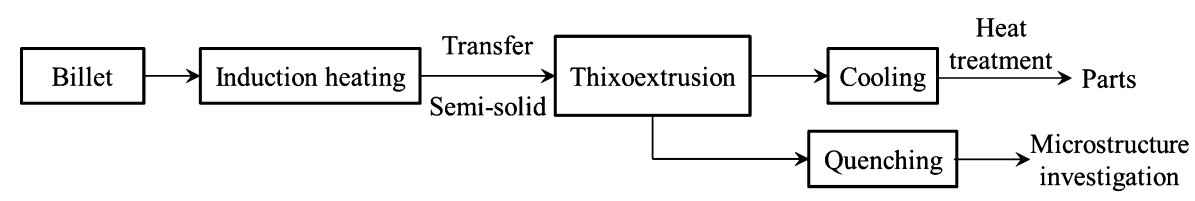

Fig. 1. Schematic view of thixoextrusion layout.

studied by many researchers as a potential manufacturing process for industrial components (Bigot et al., 2013). In addition, interest in the industrial application of steel thixoforming is on the rise for various reasons: the low forming load during thixoforming as compared to that in classical forging processes (Cezard et al., 2007), some complex parts can be produced with fewer forming steps (Bigot et al., 2013), prolonged die life due to less thermal shock, good mechanical properties with less porosity as compared to the casting process.

A material with a relatively low solidus temperature, large semisolid area (range between liquidus temperature $T_{L}$ and solidus temperature $T_{S}$ ) and low temperature sensitivity is always preferable for steel thixoforging. Various researchers have investigated the thixoformability of several grades by different approaches. The results show that X210CrW12, 100Cr6, C38LTT, M2 in particular are suitable. Gu et al. (Gu et al., 2014) performed in situ high energy X-ray microtomography and high temperature Confocal Laser Scanning Microscope (CLSM) experiments on different steel grades to study the microstructure evolution during heating to the semi-solid state from solid state for thixoforging process. It was found that, for M2, the liquid rich in alloying elements $(\mathrm{Cr}, \mathrm{Mo}, \mathrm{W})$ appeared mainly along the grain boundaries during heating to the semi-solid state. An interconnected liquid network surrounding the globular solid grains was formed with increasing temperature. After cooling, the liquid phase transformed to new carbides with exactly the same size, location and chemical composition. This was very interesting because it meant that there was hardly any diffusion of alloying elements during cooling at a relative small cooling rate $\left(\sim 200^{\circ} \mathrm{C} / \mathrm{min}\right)$; it was possible to evaluate the volume fraction of liquid by considering the volume fraction of carbides after quenching M2 from the semi-solid state. That's why, M2 was chosen in this work. The present study investigates thixoextrusion of M2 high-speed tool steel grade at a liquid fraction between $10 \%$ and $30 \%$ using a mechanical press. The aim of this investigation is to show and discuss some results of thixoextrusion including microstructure, load and material flow. The development of microstructure from as-annealed conditions to semi-solid state via partial remelting is presented. Moreover, load-displacement curves as well as the material flow are discussed in relation to the microstructure.

\section{Experimental procedures}

\subsection{Thixoextrusion procedure}

Fig. 1 gives a schematic view of thixoextrusion experiments. All the billets were heated to the semi-solid state using an induction heating system and then transferred to a mechanical press. After thixoextrusion, they were quenched for microstructure investigation. During the experiments, an acquisition system was used to record both the temperature and the forming load.

The thixoextrusion experiments were carried out using the mechanical press PRESSIX located at the Arts et Métiers ParisTech Metz center to extrude a cup-shape part as shown in Fig. 2(a). This press can provide a maximum load of $500 \mathrm{kN}$ with a maximum forming speed of $485 \mathrm{~mm} / \mathrm{s}$. Fig. 2(b) shows the principle of the extrusion set-up. The thixoextrusion die was axisymmetric. The set-up was clamped at the bottom of the press. The dies were made of tool steel X38CrMoV5. Considering the die geometry and the manufacturing cost, the induction coil was not assembled in the die for heating the billet to the desired process temperature. Before transporting the billet during each thixoextrusion test, a tool protector coating (Acheson Pluviograph D31A) was sprayed on the tool surface to protect it against wear and chemical attack on the die material. In this study, extrusion was carried out immediately when the billet reached the desired temperature between $1290^{\circ} \mathrm{C}$ and $1340^{\circ} \mathrm{C}$. Several parameters (temperature, displacement of die, forming load) were measured and controlled during extrusion; the die temperature also varied between $20^{\circ} \mathrm{C}$ and $350^{\circ} \mathrm{C}$. In order to obtain these measurements, an 8-channel acquisition system PCI6024E National Instruments was used ( $\pm 0.3 \%$ error at full scale). The collected data could be easily transferred into Excel for data analysis.

\subsection{Material}

The material used for thixoextrusion was a commercially produced M2 high-speed tool steel which had been hot rolled at a temperature $\sim 1100^{\circ} \mathrm{C}$, tempered at $\sim 700^{\circ} \mathrm{C}$ for $4 \mathrm{~h}$ and subsequently triple annealed at $\sim 540^{\circ} \mathrm{C}$ for $1 \mathrm{~h}$ before furnace cooling to (a)

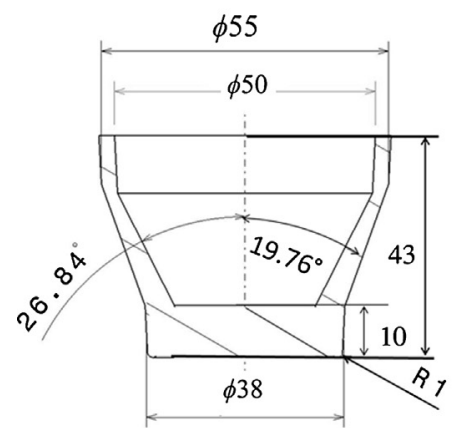

(b)

(1)

(2)

(3)

(4)

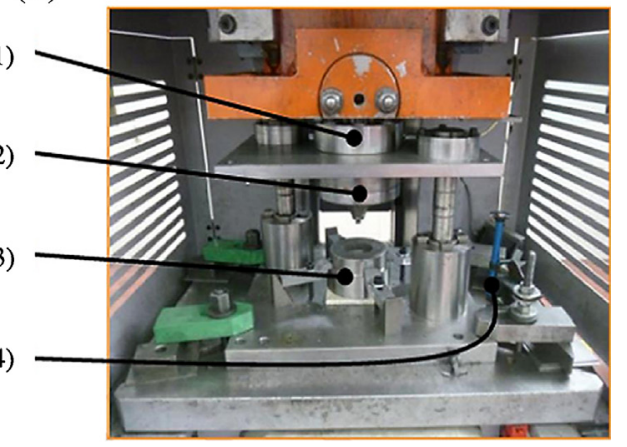

Fig. 2. Illustration of (a) the geometry of the part and (b) the extrusion set up. (1) Load sensor, (2) upper die, (3) lower die and (4) displacement sensor. 
Table 1

Chemical composition of M2 steel.

\begin{tabular}{|c|c|c|c|c|c|c|c|c|c|c|c|c|}
\hline \multirow[t]{2}{*}{ M2 } & \multicolumn{12}{|c|}{ Chemical composition (wt\%). } \\
\hline & $\mathrm{C}$ & $\mathrm{Si}$ & Mn & $\mathrm{S}$ & $\mathrm{P}$ & $\mathrm{Ni}$ & $\mathrm{Cr}$ & Mo & $\mathrm{Cu}$ & V & W & $\mathrm{Fe}$ \\
\hline Nominal & 0.85 & 0.035 & 0.25 & $\leq 0.04$ & $\leq 0.04$ & 0.2 & 4.1 & 5.0 & 0.1 & 1.9 & 6.4 & Balance \\
\hline
\end{tabular}

room temperature by the manufacturer ThyssenKrupp. Its chemical composition is given in Table 1.

\subsection{Differential Scanning Calorimetry (DSC)}

DSC analyses were performed to estimate the liquid fraction as a function of temperature. Some samples $3 \mathrm{~mm}$ in diameter and $1.5 \mathrm{~mm}$ long were machined from several billets in various positions in order to minimize the possibility of getting non-representative results due to possible variations of local composition due to the segregation in longitudinal direction. The experiments were performed using a NETZSCH 404 C Pegasus ${ }^{\circledR}$ at a heating rate of $20^{\circ} \mathrm{C} / \mathrm{min}$. Alumina with the same weight as the sample was used as a reference and Argon was applied during heating in order to prevent oxidation. The solidus, liquidus and liquid fraction of material were determined by the method indicated in (Tzimas and Zavaliangos, 2000a).

\subsection{Partial remelting by induction}

Prior to the thixoextrusion, in order to determine the appropriate conditions for a successful thixoextrusion, some heating trials were performed in the laboratory LCFC at the Arts et Métiers ParisTech, Metz using an induction heating system; it is a highheating speed technique with a good repeatability. The generator (brand CELES) can provide a maximum power of $50 \mathrm{~kW}$ in a frequency interval, ranging from 20 to $100 \mathrm{kHz}$. The induction heating approach was performed on billets $35 \mathrm{~mm}$ in diameter and $34 \mathrm{~mm}$ in height using a purpose-designed induction coil. During heating, a piece of Nefacier 1500 disc approximately $8 \mathrm{~mm}$ in thickness (based on ceramic fibers with a low content of non-fibrous ceramic particles) was placed between the billet and the ceramic holder to reduce the heat losses (Fig. 3(a)). During the billet transportation stage, the clamps were also covered with a Nefacier 1500 disc to decrease the thermal exchange between the billet and the clamps.
Three S-type thermocouples were placed in different positions for monitoring or recording the temperature of the billet as shown in Fig. 3(b). Considering the skin effect of induction heating and the heat exchange between the billet and air, various heating cycles were tested for obtaining a homogeneous temperature field with a short heating time. A three-step heating cycle of $\sim 5.5 \mathrm{~kW}(70 \mathrm{~s})$, $1.8 \mathrm{~kW}(60 \mathrm{~s})$ and $1.6 \mathrm{~kW}(80 \mathrm{~s})$ was finally adopted for this billet geometry for thixoextrusion (Fig. 4(a)). A temperature decrease of $\sim 30^{\circ} \mathrm{C}$ and $\sim 10^{\circ} \mathrm{C}$ near surface and in the middle of the billet respectively were observed in the figure due to the transportation time ( $\sim 9-11 \mathrm{~s})$ caused by radiation losses and thermal exchange between the material and the clamp. Various heating trials under the same conditions were performed in order to check the reproducibility of the heating cycles. Fig. 4(b) compares the temperature evolution in the center of the billets for two trials with the same heating cycle showing the good reproducibility of the heating cycle. There were only small variations in temperature at the beginning of the heating stage and during the holding stage. However, due to the accuracy of the thermocouples $\left( \pm 2.5^{\circ} \mathrm{C}\right)$ and the temperature controlling around the process temperature, a difference of $10^{\circ} \mathrm{C}$ is considered to be acceptable in an industrial steel thixoforging process.

\subsection{Image analysis}

The microstructure was characterized by using an optical microscope and a Jeol 7001FLV scanning electron microscope (SEM). Energy dispersive spectrometry (EDS) analyses were performed with an Oxford INCA System to study the distribution of the different alloying elements in order to investigate the former liquid phase. All samples observed were etched using $2 \%$ Nital. The grain size was measured following the ASTM E112-96 standard. The liquid fraction was evaluated using the software ImageJ (automatic image analysis) on micrographs with small magnification obtained via optical microscope. During the image analyses, a compromise in (a)

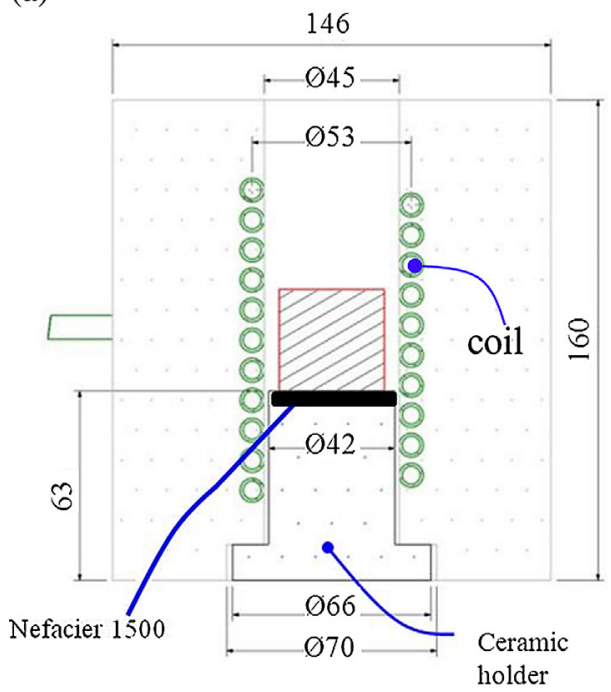

(b)

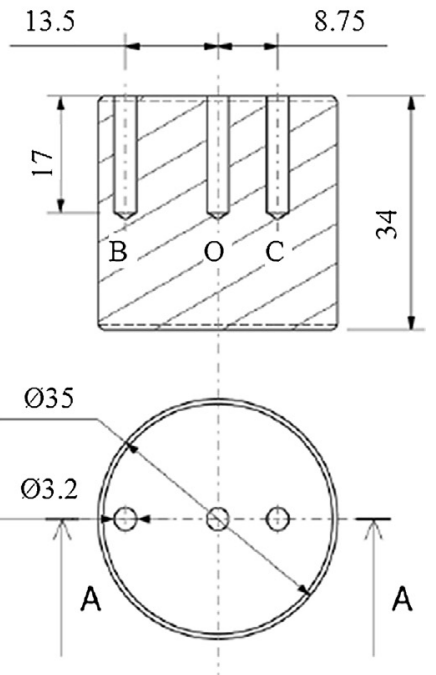

Fig. 3. Schematic of (a) the cylindrical billet position during heating process and (b) the thermocouples position in the billet. 

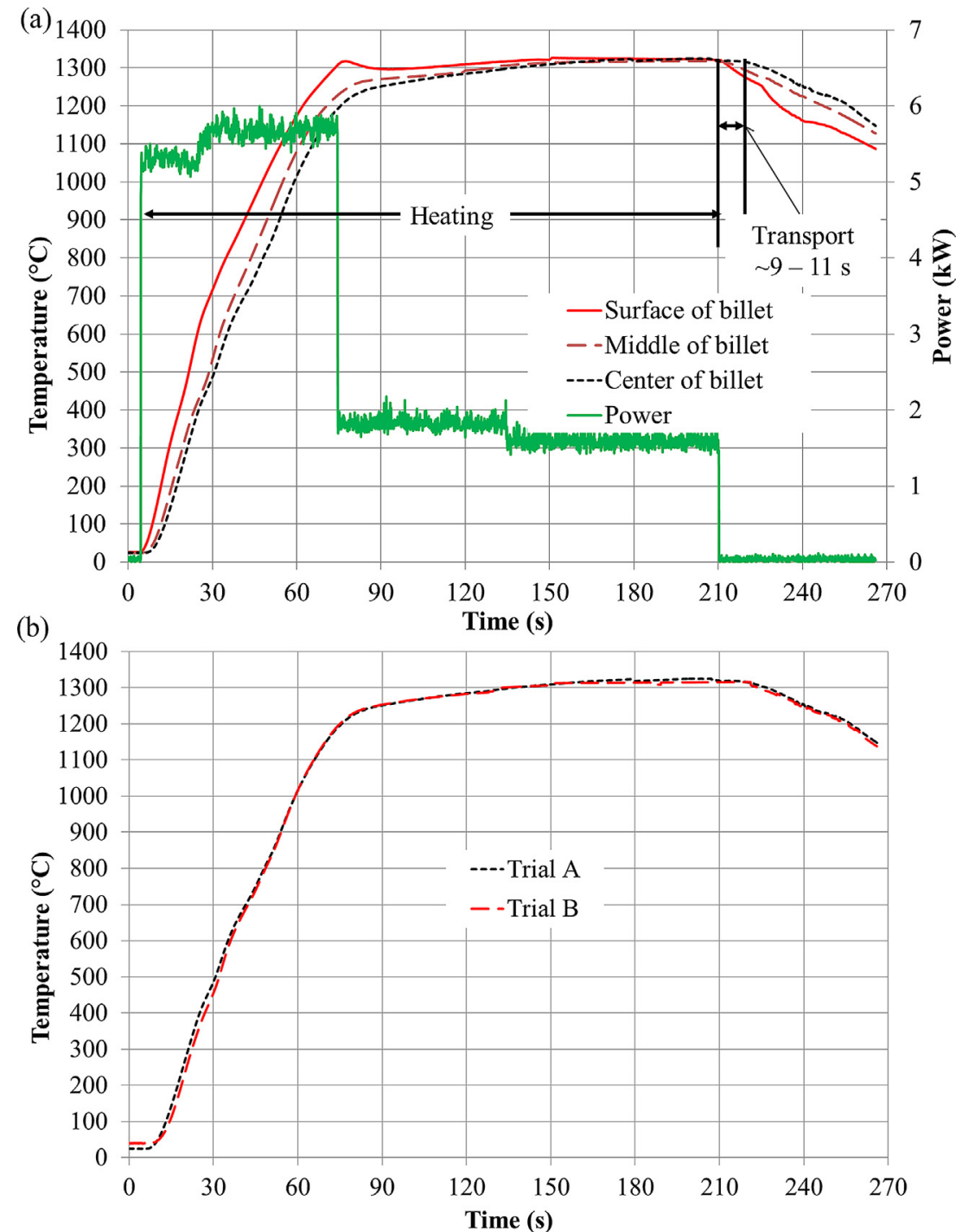

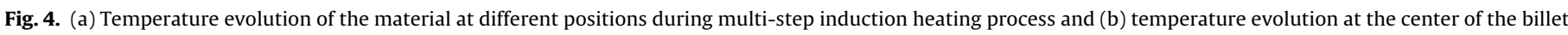
during two trials with the same heating cycle.

magnification was made: the magnification should be high enough to clearly distinguish the spheroidal solid from eutectic phases but low enough to cover sufficient area for minimizing the error due to inhomogeneous distribution of the phases and permitting rapid analysis of the micrograph.

\section{Results and discussion}

\subsection{Material in as-received state}

The optical micrographs of the as-received M2 high-speed tool steel obtained on transversal and longitudinal sections are presented in Fig. 5. The microstructure of the material in the asreceived state consists in a ferritic matrix with fine carbide particles (confirmed by EDS) (Gu et al., 2012). The grain size is $\sim 10 \mu \mathrm{m}$. As mentioned in section 2.2 , the material underwent a complicated manufacturing process: hot rolling, tempering and triple annealing at various conditions which lead to this complex microstructure. As compared to that of the non-annealed M2 steel, the microstructure is much more homogeneous and the microsegregation effect is reduced a lot. However, due to the high content alloying elements such as $\mathrm{W}$ and Mo that have a low solubility and a low diffusion rate, the microstructure is not fully homogenized. Some carbides segregation bands parallel to the working direction along the billet are still due to the rolling process.

\subsection{Microstructure in the semi-solid state prior to thixoextrusion}

DSC analyses have been carried out to estimate the solidus, liquidus and the liquid fraction of M2 in the semi-solid state using the set-up and method mentioned above. The DSC results are shown in Fig. 6. The solidus and liquidus temperatures are estimated at $1240{ }^{\circ} \mathrm{C}$ and $1440^{\circ} \mathrm{C}$, respectively. The liquid fraction between $10 \%$ and $30 \%$ corresponds to the temperature interval [ $\left.1290-1340^{\circ} \mathrm{C}\right]$. The DSC results were useful for determining the thixoextrusion temperature range. The quenched M2 samples from different temperatures were also used for further liquid fraction estimation. For image analysis, the liquid fraction of one sample is an average value estimated from various positions in both longitudinal and transversal sections. Fig. 6 compares the liquid fraction as a function of temperature for M2 steel obtained by image analysis and DSC. The DSC curve presents a liquid fraction in the good range for thixoforging between $1300^{\circ} \mathrm{C}$ and $1340^{\circ} \mathrm{C}$. Moreover the variation is small in this range which is good for temperature controlling 


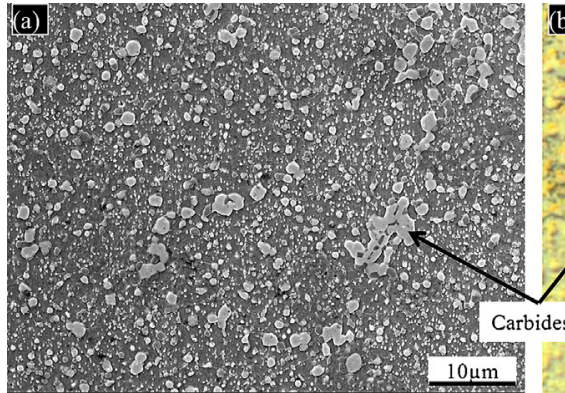

Transversal direction

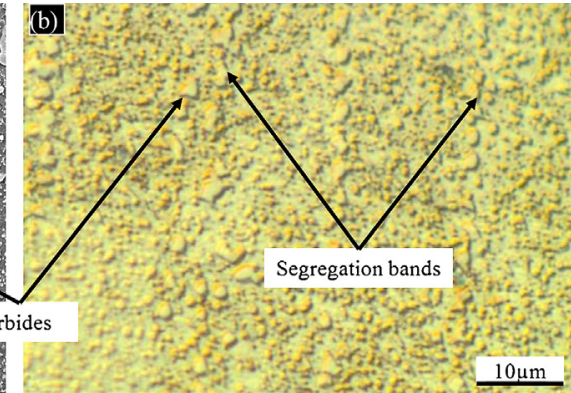

Longitudinal direction

Fig. 5. SEM (a) and optical (b) micrographs of the as-received M2 steel in transversal and longitudinal directions.

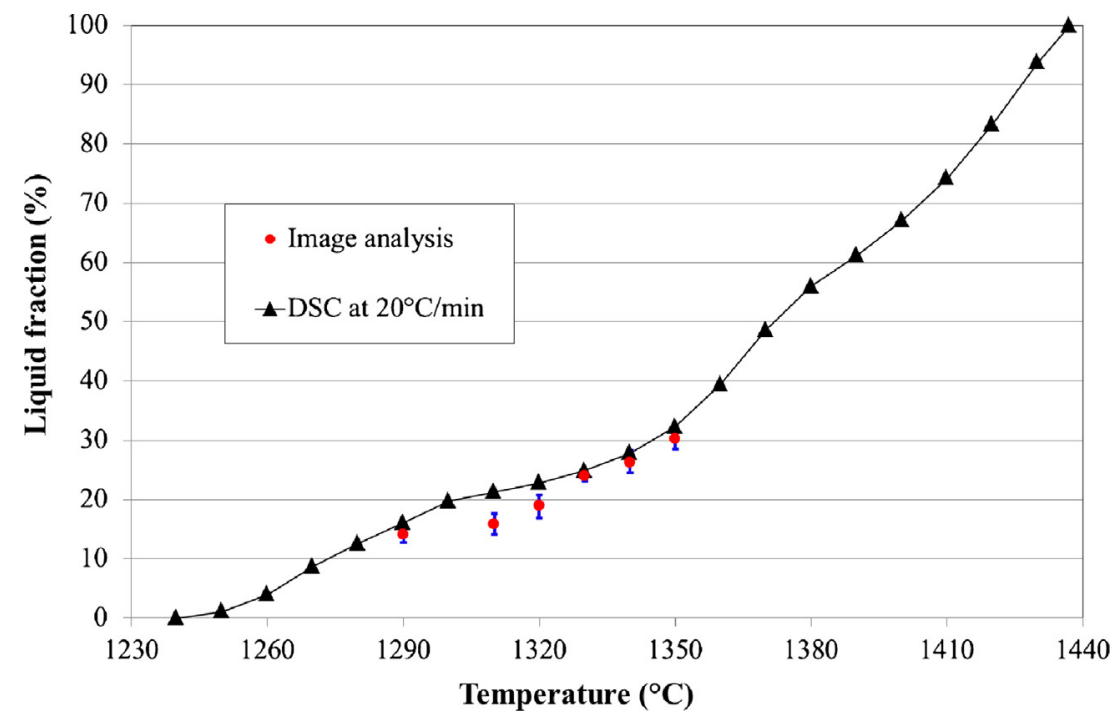

Fig. 6. Liquid fraction as a function of temperature obtained by DSC and image analysis.

and reproducibility in industrial conditions. The liquid fraction evaluated by image analysis is a little smaller than that of DSC. There are several issues which may lead to this difference in liquid fraction. The first issue is the sufficiency of cooling rate. Although the CLSM results (Gu et al., 2014) show that the former liquid zones can be preserved at a low cooling rate observed by naked eyes, non-instantaneous solidification may also occur during quenching the material from semi-solid state, resulting in further solidification of liquid. Moreover, the induction heating process may also cause a lower liquid fraction due to the penetration effect, as shown in Fig. 7 which presents the liquid fraction in different positions considering a billet after quenching. The liquid fraction is

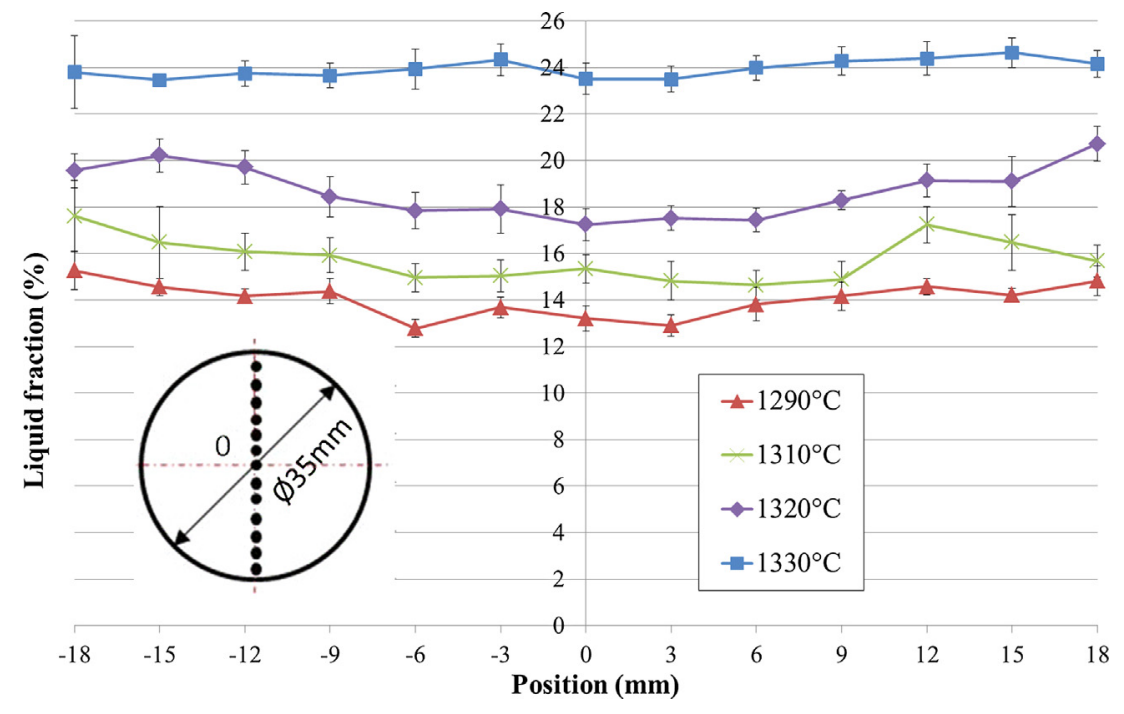

Fig. 7. Liquid fraction evaluation on transversal sections at various temperatures. 

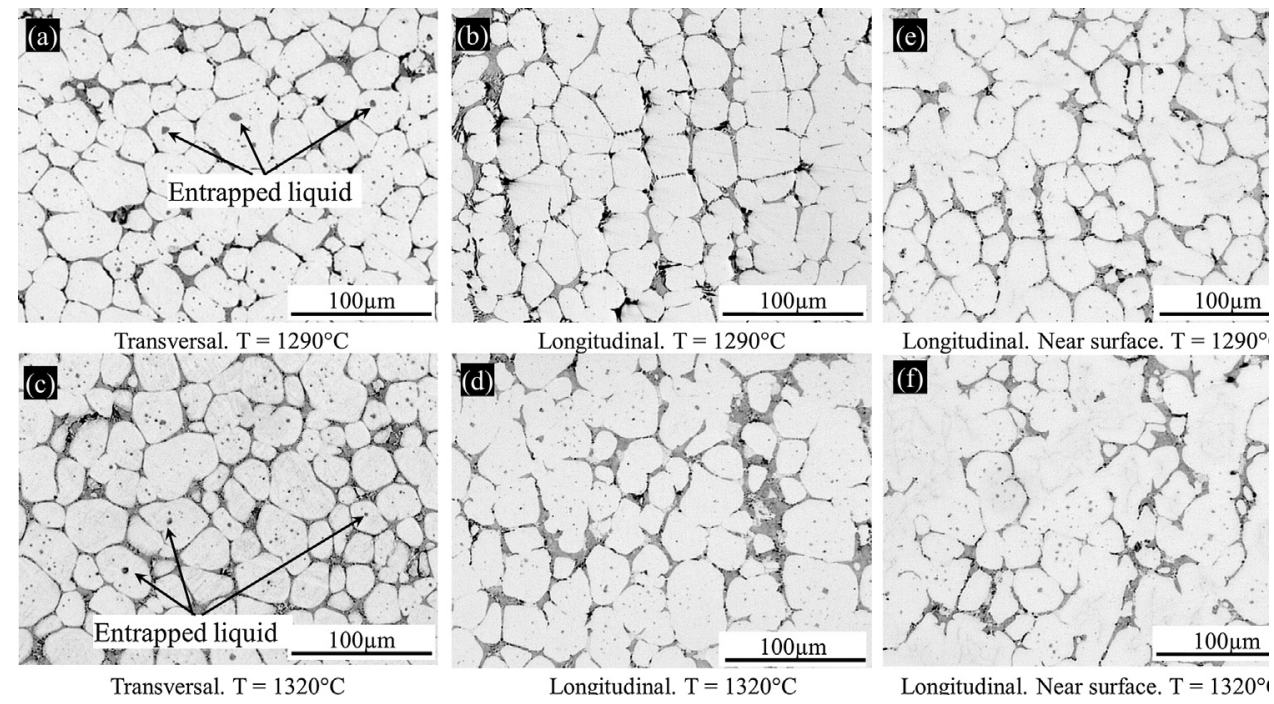

Fig. 8. Microstructure of M2 steel in the semi-solid state in various sections (optical micrographs).

decreasing with decreasing radius but the variations are relatively low. As mentioned in section 2.4, it is quite challenging to have a totally homogeneous temperature distribution in the billet. Thus, the average liquid fraction evaluated by image analysis is smaller than that calculated by DSC. Finally, the heating rate with these two techniques is different $\left(20^{\circ} \mathrm{C} / \mathrm{min}\right.$ for DSC and $\sim 375^{\circ} \mathrm{C} / \mathrm{min}$ during induction heating), which can also influence the liquid fraction (Atkinson and Rassili, 2010).

The quenched billets from the induction trials could be used not only to estimate the liquid fraction as a function of temperature but also to study the microstructure evolution in the semi-solid state. Fig. 8 presents some representative micrographs of the material heated at various temperatures. There is a great change in morphology in the semi-solid state as compared to that in the as-received state. There is a significant grain growth (from $\sim 10 \mu \mathrm{m}$ at room temperature to $\sim 40 \mu \mathrm{m}$ at $\sim 1300^{\circ} \mathrm{C}$ ) and the solid grains are surrounded with the new formed interconnected large carbides which correspond to former liquid in the semi-solid state.

The grain growth is thermally activated, grains grow with increasing temperature and holding time. However, there is not a significant grain growth when the material is in the semi-solid state as compared in Fig. 8: the average grain size at $1290^{\circ} \mathrm{C}$ is similar to that at $1320^{\circ} \mathrm{C}$. One reason for the lack of significant changes in grain size can be continuous presence of MC complex carbides in eutectic mixture, which can block grain coarsening. Another reason may be related to the liquid fraction. MansonWhitton et al. (2002) stated that the grain coarsening rate should decrease with increasing liquid fraction because once a continuous liquid path is present around the solid phase, the energy is used for the increasing of liquid instead of grain growth. The coarsening of semi-solid alloys with a liquid fraction can be better described in terms of the migration of grain boundary liquid films (Annavarapu and Doherty, 1995) which separate the grains than by considering diffusion fields around isolated solid grains stated by Lifshitz-Slyozov-Wagne (Lifshitz and Slyozov, 1961). The agglomerated particles cause particle coalescence in order to reduce the surface energy. During heating, small particles are dissolved to large particles by the solute diffusion (Ostwald ripening), resulting in the grain growth. In addition, the grain coalescence is also thought to be an important factor leading to a greater grain size, as stated by Tzimas and Zavaliangos (2000b). Fig. 8(e) and (f) presents the evidence of grain coalescence in the semi-solid state. During induction heating, the material near surface is heated up faster and the final temperature is higher due to the penetration effect. Resulting from the gravity of the billet, the solid grains at the bottom get into contact with each other, favoring coalescence. However, the grain size of M2 is much smaller as compared to that of low alloying steel, such as C38LTT (Becker et al., 2010b), 100Cr6 (Püttgen et al., 2007). The low grain growth rate is considered to be related to the carbide pinning effect.

In addition, some intragranular liquid droplets are observed in the material at various temperatures as shown in Fig. 8. These droplets may originate from the undiffused carbides in the austenitic matrix. As well known, this intragranular liquid do not contribute to 'lubricate' the material during thixoforging; it is also observed in some other rolled or extruded materials such as $\mathrm{Al}$ 7075 (Neag et al., 2012), HP9/4/30 (Omar et al., 2005) and 100Cr6 (Püttgen et al., 2005). Although rolled or extruded materials may not be ideal for thixoforging process because of the presence of entrapped liquid (Fig. 8), spherical grains can be easily obtained without much holding time in the semi-solid state thanks to the non-dendritic initial microstructure.

As shown in Fig. 8, the spherical microstructure is obtained at various temperatures by induction heating process. The shape factor F calculated considering (Eq. (1)) of the solid grains at various temperatures is similar: around 0.87 .

$F=\frac{4 \pi A}{U^{2}}$

where $A$ and $U$ are the area and the circumference of grains, respectively.

When $F=1$, all grains are spherical.

Overall, the morphology of the microstructure at various temperatures is similar, with only variations in liquid films thickness. Normally, with increasing liquid fraction, the thickness of liquid film should increase, resulting in a higher liquid fraction. The liquid ejection would probably occur at a higher liquid fraction (Becker et al., 2010a). Thus, the microstructure in the temperature interval $\left[1290-1340^{\circ} \mathrm{C}\right]$ is considered to be suitable for thixoforging process. The details of the microstructure evolution during partial melting from solid state to semi-solid state can be found in $(\mathrm{Gu}$ et al., 2012).

\subsection{Thixoextrusion tests}

From the microstructure results of partial melted M2 billets, a conventional thixoformable microstructure of spherical solid grains surrounded by liquid phase could be obtained by direct 


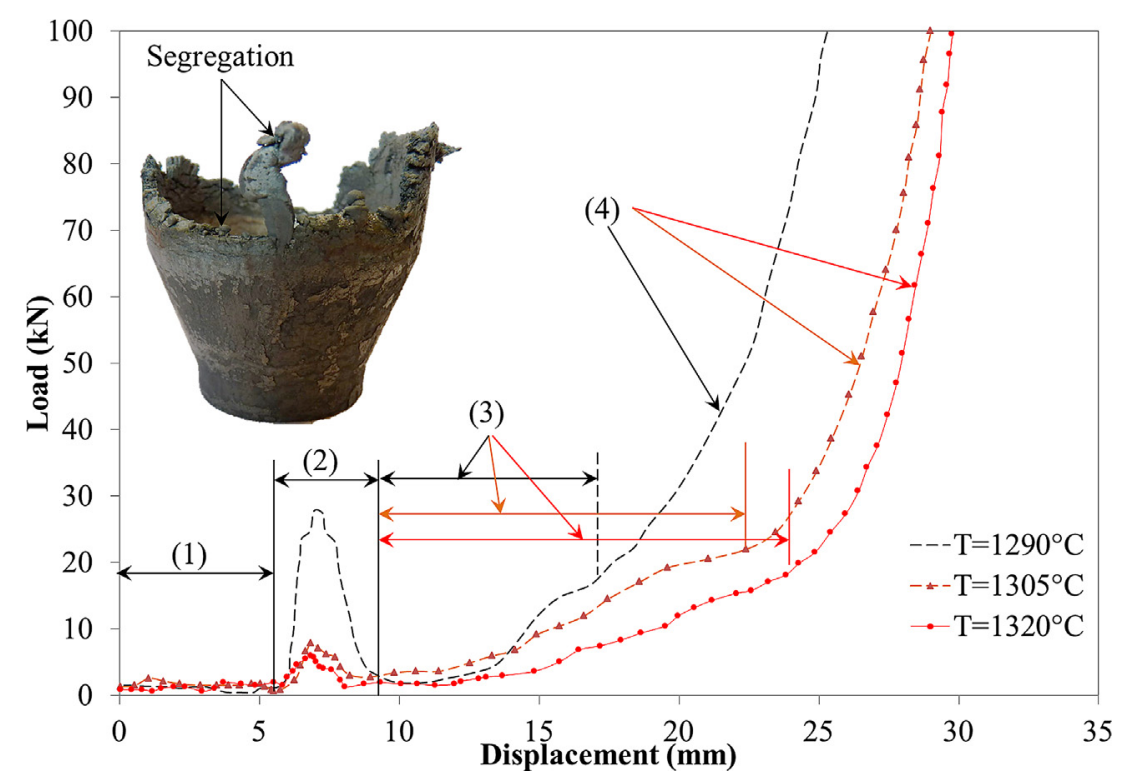

Fig. 9. Load-displacement curves during thixoextrusion at different temperatures.

heating the as-received billet to the semi-solid state without holding time. As calculated from the quenched M2 billets, the liquid fraction at $1290^{\circ} \mathrm{C}$ and $1340{ }^{\circ} \mathrm{C}$ ranges from $10 \%$ to $30 \%$. In addition, the liquid fraction does not vary a lot in this temperature interval for M2, which is good for temperature controlling in the thixoforming process.

Some thixoextrusion tests were therefore performed at various temperatures ranging from $1290^{\circ} \mathrm{C}$ to $1340^{\circ} \mathrm{C}$. As shown in Fig. 4 , the surface of the billets heats up first and rapidly due to the penetration effect and high heating power. The core of the billet is heated by thermal conduction from the surface, resulting in a low increase in temperature. At the end of the heating process, the temperature across the billet is relatively homogeneous with a maximum temperature difference of about $10^{\circ} \mathrm{C}$. In addition, the solid skin surface caused by the thermal exchange and radiation losses is helpful to support the billet itself, preventing its collapse.

Fig. 9 presents the load-displacement curves of the thixoextruded cup-shape parts at various temperatures $\left(1290^{\circ} \mathrm{C}, 1305^{\circ} \mathrm{C}\right.$ and $1320^{\circ} \mathrm{C}$ ) using a billet $35 \mathrm{~mm}$ in diameter and $34 \mathrm{~mm}$ in height, with a cold die. The obtained parts have good shapes. However, the surface quality due to oxidation needs to be improved. The part shown in Fig. 9 is extruded at $1320^{\circ} \mathrm{C}$ with an average forming speed of $\sim 320 \mathrm{~mm} / \mathrm{s}$. The curves only show part of the extrusion stroke. The trend is similar: after a first peak at the beginning of the extrusion process, the load increases with increasing displacement. Depending on the evolution of the force, the load vs displacement curve can be divided into 4 stages as shown in Fig. 9. Stage (1) corresponds to the motion of the punch until the first contact with the billet. A peak load appears just after stage (1), corresponding to stage (2). After the peak, the forming load increases slowly in stage (3) and greatly in stage (4) when the material fills the die. In addition, it is also found that an increase in the temperature (or liquid fraction) results in a decrease in the first load peak and forming load. This is consistent with literature when considering the semi-solid forming process for different metallic materials such as simple compression of $\mathrm{Sn-Pb}$ alloy (Kopp, 2003), aluminum alloy (Kang et al., 1999), steel alloy (Shimahara and Kopp, 2004) and extrusion of steel grade C38LTT (Becker et al., 2010b). The load vs displacement curves from the compression tests for different materials are similar in evolution pattern. Before the contact with the billet, the load value is around $0 \mathrm{kN}$, with small variations due to the clamping force on the die and the accuracy of the load sensor. The first peak appears when the billet starts being deformed; this load may be used for the breakdown of the solid skeleton, the decohesion of the insufficiently wetted grain boundaries or the fracture of the oxide layer. In this stage, it can also be observed that the peak load decreases with increasing temperature. As the liquid fraction increases, the strength of the solid skeleton decreases; it is more easily broken. In addition, with increasing liquid fraction, the space between unconnected particles may enlarge. The solid grains are therefore easier to rotate or pass each other, leading to a decrease in viscosity. Liu et al. (Liu et al., 2003) and Omar et al. (Omar et al., 2005) also investigated the influence of holding time on the peak load by performing different experiments on various materials. They stated that the peak load decreases with increasing holding time. After the first peak, the load decreases significantly with the penetration of the punch into the material. The material is thought to have a thixotropic behavior. As soon as the structure is broken down, the solid grains are surrounded by the liquid phase. Depending on the liquid fraction, the material shows a thixotropic or partial thixotropic behavior. With further penetration of the punch, the load increases rapidly. In this stage, the material experiences back extrusion and die filling. Moreover, the surface quality of the parts is not good due to the oxidation appearing during the induction heating process. Some liquid segregations are also observed in several thixoextruded parts, especially in the longitudinal direction, leading to a possible liquid ejection. During extrusion, the liquid follows a path that requires the lowest energy. Part of this liquid can be squeezed out of the material when reaching the billet surface. Finally, a warm die $\left(\sim 350^{\circ} \mathrm{C}\right)$ has also been tested during some extrusion experiments. As compared to a cold die, no big difference has been observed in the load profiles and the cup shape. The load does not decrease as expected when using a warm die; the temperature $\left(\sim 350^{\circ} \mathrm{C}\right)$ may not be sufficient to improve the material flow.

\subsection{Microstructure in different zones}

After extrusion, the parts have been sectioned in the longitudinal direction for a morphology investigation. Table 2 shows the microstructure of one part $\left(1320^{\circ} \mathrm{C}\right)$ in different zones. $\mathrm{Fg}$ and $\mathrm{Fl}$ are the average shape factor and liquid fraction, respectively.

The microstructure is different in the different zones of the thixoextruded cup. The difference in microstructure in various 
Table 2

Microstructure in different positions (optical micrographs).

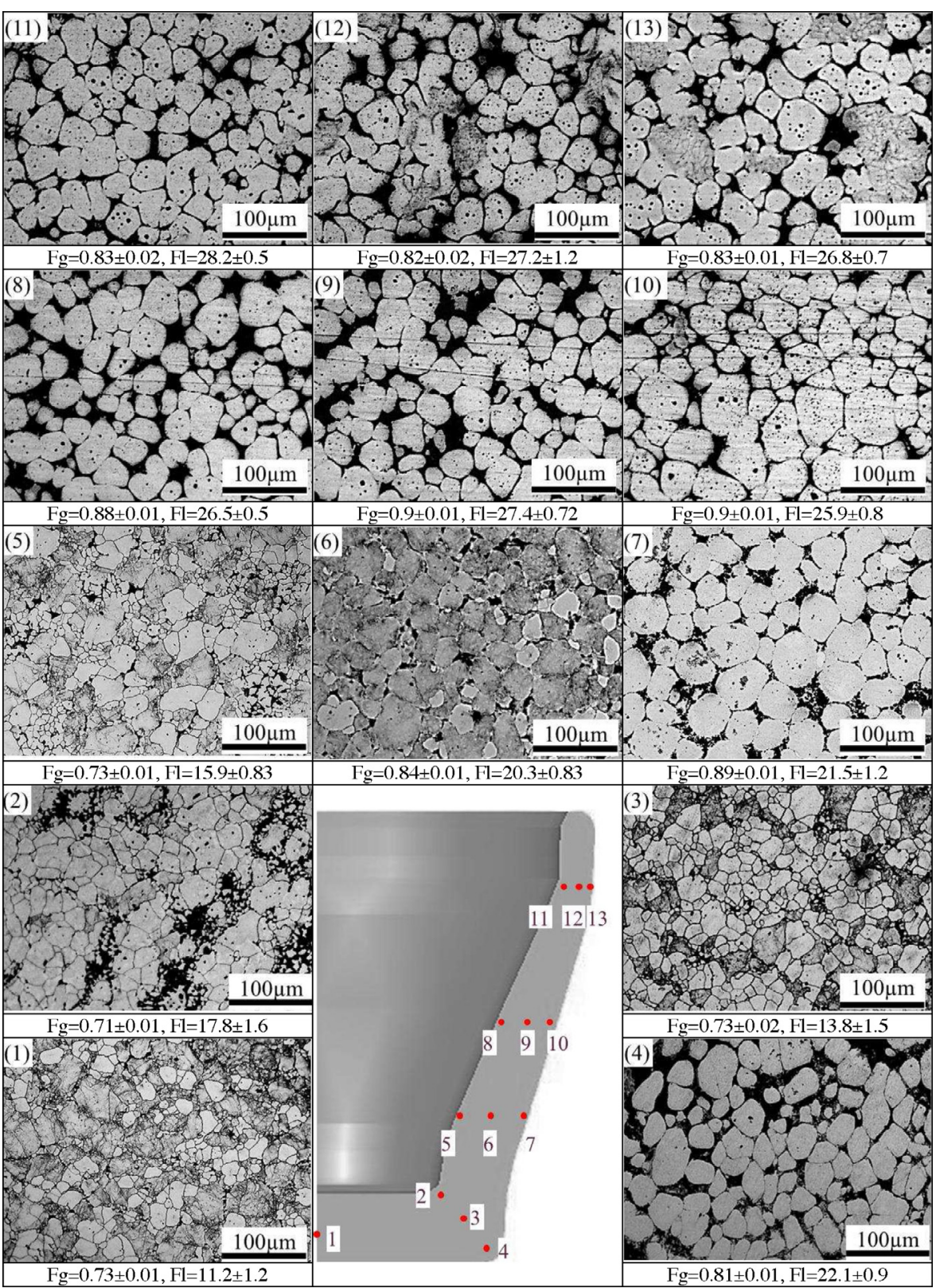

zones is thought to be related to the part geometry and at the liquid fraction associated. The results of quantitative image analysis in different zones show that the liquid fraction increases from the bottom of the cup (around 11\%) up to $\sim 27 \%$ at the top. This increase in liquid fraction was also observed on aluminum thixoextruded parts by Neag et al. (2012). Globular solid grains surrounded by liquid phase are observed in the outer surface and in the zones above the intermediate height of the cup (above point 5 ). The microstructure at the bottom (point 1,3) and inside corner (point 2) of the cup shows equiaxed solid grains with less liquid, due to the plastic deformation of grains in these zones. The low liquid fraction in point 1 corresponds to the zone in which the temperature was lowest during heating because the heat transfer with the tool was important. For point 2, the heat transfer between the billet and the upper punch as well as the low material flow explain the low liquid fraction and the equiaxed solid grains. In zones 4, 7, 10, 13 near the outer edges of the grains are larger and globular because the material at the periphery of billet is warmer during the heating process. The spheroidal grains imply that the semi-solid zone was reached during heating and that the material was less deformed during the forming process. A liquid segregation is also observed, mainly located in zone 2 . As discussed above, there are four stages in the extrusion process. After breaking down of the solid skeleton, most of the grain boundaries are wetted by the liquid phase. As the deformation proceeds, the liquid phase is pressed to the edge (like water out of a sponge), resulting in a decrease of the liquid fraction in the center. With the deeper penetration of the punch into the material, the liquid fraction in the center still decreases, while in the filling zone (in the side walls of the cup), the liquid fraction is relatively high. Therefore, during extrusion, the material flow in the filling zone is driven by the liquid flow combined with the rearrangement of solid grains. Due to the geometry of the extruded part, the diameter of the flow front zones increases with the height of the cup; the volume of material to be supplied also 
increases. This increase can be easily accommodated by the liquid phase, since the liquid is much more fluid than the solid. In the inside corner of the cup, the solid grains can get into contact with each other, blocking the flow of the liquid phase during extrusion. As a consequence, the segregation of liquid phase becomes evident in this zone; meanwhile, heat is generated due to the significant deformation in the inside corner of the cup, resulting in a higher temperature and therefore the increasing of liquid fraction in this zone. However, the segregation phenomenon remains small because of the low quantity of liquid in this zone. The liquid fraction in the center decreases with increasing deformation. When the solid grains start getting into contact with each other, plastic deformation occurs as shown in Table 2 ( 1 and 3). From the curves of forming load as a function of displacement, it can also be concluded that the forming load for plastic deformation of grains is much higher than for grains sliding and liquid flow. During extrusion, the material in zone 4 is similar to that in the semi-solid state prior to thixoextrusion, which indicates that the material in this zone is not deformed. Omar et al. (Omar et al., 2009) also investigated the thixoformability of M2 steel grade, but they mainly focused on higher liquid fraction between 30\% and 50\%. Comparing the microstructure in the semi-solid state in the two studies, the microstructure is similar: spherical solid grains (average grain size $\sim 40 \mu \mathrm{m}$ ) with surrounded liquid phase. With such a microstructure, an increase of $10 \%$ in liquid fraction (from $20 \%$ to $30 \%$, for example) leads to a $2 \mu \mathrm{m}$ increase in thickness of liquid films. Since the cups can be thixoextruded at a lower liquid fraction (10-30\%), it is possible to say that the liquid fraction range for a successful thixoforming process can be enlarged from $10-50 \%$, depending on the material microstructure in the semi-solid state.

\section{Conclusions}

This work showed the possibility to thixoextrude a M2 highspeed tool steel at processing temperatures ranging from $1290^{\circ} \mathrm{C}$ to $1340{ }^{\circ} \mathrm{C}$ which corresponds to a liquid fraction between $10 \%$ and $30 \%$. Despite the relative small liquid fraction, the parts could be successfully extruded in the semi-solid state. By induction heating, the conventional globular microstructure surrounded by liquid phase was obtained directly from the as-received state. By studying the load-displacement curves, four processing stages were observed: (1) prior to thixoextrusion stage, (2) structure breakdown stage, (3) thixotropic flow stage and (4) plastic deformation of solid grains stage. At higher temperature (or higher liquid fraction), the first peak load and the final forming load decreased whereas the thixotropic flow stroke increased. According to the microstructure in different zones of the thixoexturded cups, three material flow mechanisms were also proposed: the breakup of microstructure mechanism dominates the stage-stage (2); the flow of liquid phase combined with the sliding between solid grains prevail on a relatively larger amount of deformation-stage (3) and are followed by the plastic deformation of solid grains at bottom of the cup as the dominant mechanism-stage (4). Finally, thixoextrusion with a warm die $\left(\sim 350^{\circ} \mathrm{C}\right)$ was also tested, but the results showed that a die temperature below $\sim 350^{\circ} \mathrm{C}$ may be not sufficient to improve the material flow. This work showed that the load signals and the material flows were influenced by processing temperatures/liquid fraction and the microstructure. Further work on numerical simulations with a proper model for semi-solid forming (load, material flow, behavior law) is ongoing; it will help us to better master the thixoforging process for steels.

\section{Acknowledgements}

The authors warmly thank HENRION Emerik and GYSS Olivier at Arts et Métiers ParisTech CER Metz for their technical support.

\section{References}

Annavarapu, S., Doherty, R.D., 1995. Inhibited coarsening of solid-liquid microstructures in spray casting at high volume fractions of solid. Acta Metall. Mater. 43, 3207-3230.

Atkinson, H.V., Rassili, A., 2010. A review of the semi-solid processing of steel. Int. J. Mater. Form. 3, 791-795

Becker, E., Bigot, R., Langlois, L., 2010a. Thermal exchange effects on steel thixoforming processes. Int. J. Adv. Manuf. Technol. 48, 913-924.

Becker, E., Favier, V., Bigot, R., Cezard, P., Langlois, L., 2010b. Impact of experimental conditions on material response during forming of steel in semi-solid state. J. Mater. Process. Technol. 210, 1482-1492.

Bigot, R., Becker, E., Langlois, L., 2013. Some approaches on industrialization of steel thixoforging. Solid State Phenom. 192-193, 521-526.

Bulte, R., Bleck, W., 2004. Effects of pre-processing on thixo-formability of steel grade 100Cr6. Steel Res Int. 75, 588-592.

Cezard, P., Bigot, R., Favier, V., Robelet, M., 2007. Thixoforming of steel: experiments on thermal effects. In: Banabic, D. (Ed.), Advanced Methods in Material Forming. Springer, Heidelberg, pp. 309-320.

Chayong, S., Atkinson, H.V., Kapranos, P., 2005. Thixoforming 7075 aluminium alloys. Mater. Sci. Eng., A 390, 3-12.

Dutkiewicz, J., Rogal, Ł., Sołek, K., Mitura, Z., Kapranos, P., 2010. Thixoforming of spray formed M2 tool steel. Int. J. Mater. Form. 3, 755-758.

Gu, G.C., Pesci, R., Langlois, L., Becker, E., Bigot, R., Guo, M.X., 2014. Microstructure observation and quantification of the liquid fraction of M2 steel grade in the semi-solid state combining confocal laser scanning microscopy and X-ray microtomography. Acta Mater. 66, 118-131.

Gu, G.C., Pesci, R., Becker, E., Langlois, L., Bigot, R., Scheel, M., 2012. Quantification and localization of the liquid zone of partially remelted M2 tool steel using X-ray microtomography and scanning electron microscopy. Acta Mater. 60, 948-957.

Haga, T., Suzuki, S., 2001. Casting of aluminum alloy ingots for thixoforming using a cooling slope. J. Mater. Process. Technol. 118, 169-172.

Hogg, S.C., Atkinson, H.V., Kapranos, P., 2004. Semi-solid rapid compression testing of spray-formed hypereutectic Al-Si alloys. Metall. Mater. Trans. A 35, 899-910

Kang, C.G., Choi, J.S., Kim, K.H., 1999. The effect of strain rate on macroscopic behavior in the compression forming of semi-solid aluminum alloy. J. Mater. Process. Technol. 88, 159-168.

Kapranos, P., Kirkwood, D.H., Sellars, C.M., 1993. Semi-solid processing of tool steel. J. Phys. IV 3, 835-840.

Kenney, M.P., Courtois, J.A., Evans, R.D., Farrior, G.M., Kyonka, C.P., Koch, A.A., Young K.P., 1988. Metals Handbook, Vol. 15., ninth ed. ASM International, Metals Park, OH, pp. 327-338.

Kirkwood, D.H., Sellars, C.M., Elias Boyed, L.G., 1992. Thixotropic materials. Patent EP 0305375 B1.

Kirkwood, D.H., Suéry, M., Kapranos, P., Atkinson, H.V., Young, K.P., 2010. Semi-solid Processing of Alloys. Springer, Heidelberg, Berlin.

Kiuchi, M., Sugiyama, S., 1995. A new process to manufacture semi-solid alloys. ISI Int. 35, 790-797.

Kopp, R., 2003. Simple compression test and simulation of an $\mathrm{Sn}-15 \% \mathrm{~Pb}$ alloy in the semi-solid state. J. Mater. Process. Technol. 135, 317-323.

Legoretta, E.C., Atkinson, H.V., Jones, H., 2008. Cooling slope casting to obtain thixotropic feedstock II: observations with A356 alloy. J. Mater. Sci. 43, 5456-5469.

Lifshitz, I.M., Slyozov, V.V., 1961. The kinetics of precipitation from supersaturated solid solutions. J. Chem. Phys. Solids 19, 35-50.

Liu, T.Y., Atkinson, H.V., Kapranos, P., Kirkwood, D., Hogg, S.C., 2003. Rapid compression of aluminum alloys and its relationship to thixoformability. Metall. Mater. Trans. A 34, 1545-1554.

Manson-Whitton, E.D., Stone, I.C., Jones, J.R., Grant, P.S., Cantor, B., 2002. Isotherma grain coarsening of spray formed alloys in the semi-solid state. Acta Mater. 50 2517-2535.

Mitsure, A., Hiroto, S., Yasunori, H., Tatsuo, S., Atsushi, Y., 1996. Method and apparatus of shaping semisolid metals. Patent, EP 0745694 A1.

Moschini, R., 1992. Manufacture of automotive components by semi liquid forming process. In: Brown, S.B., Flemings, M.C. (Eds.), Proceedings of the Second International Conference on Semi-solid Processing of Alloys and Composites. MIT Boston, USA, pp. 149-158.

Neag, A., Favier, V., Bigot, R., Pop, M., 2012. Microstructure and flow behaviour during backward extrusion of semi-solid 7075 aluminium alloy. J. Mater. Process. Technol. 212, 1472-1480.

Omar, M.Z., Atkinson, H.V., Howe, A.A., Palmiere, E.J., Kapranos, P., Ghazali, M.J., 2009 Solid-liquid structural break-up in M2 tool steel for semi-solid metal processing. J. Mater. Sci. 44, 869-874.

Omar, M.Z., Palmiere, E.J., Howe, A.A., Atkinson, H.V., Kapranos, P., 2005. Thixoforming of a high performance HP9/4/30 steel. Mater. Sci. Eng. A 395, 53-61.

Püttgen, W., Bleck, W., Seidl, I., Kopp, R., Bertrand, C., 2005. Thixoforged damper brackets made of the steel grades HS6-5-3 and 100Cr6. Adv. Eng. Mater. 7 $726-735$.

Püttgen, W., Hallstedt, B., Bleck, W., Löffler, J.F., Uggowitzer, P.J., 2007. On the microstructure and properties of $100 \mathrm{Cr} 6$ steel processed in the semi-solid state. Acta Mater. 55, 6553-6560.

Rassili, A., Fischer, D., Robelet, M., Dermurger, J., Cucatto, A., Klemn, H., Walkin, B. Kalsson, M., Flü $\beta$, A., 2004. Improvement of materials and tools for thixoforming of steels. In: Alexandrou, G.G., Jorstad, J., Makhlouf, M. (Eds.), Proceedings of Eighth International Conference on Semi-solid Processing of Alloys and 
Composites. The North American Die Casting Association, Limassol, Cyprus, USA, pp. 533-543.

Shimahara, H., Kopp, R., 2004. Investigations of basic data for the semi-solid forging of steels. In: Alexandrou, G.G., Jorstad, J., Makhlouf, M. (Eds.), Proceedings of Eighth International Conference on Semi-Solid Processing of Alloys and Composites. The North American Die Casting Association, Limassol, Cyprus, USA, pp. 419-429.
Tzimas, E., Zavaliangos, A., 2000a. Evaluation of volume fraction of solid in alloys formed by semisolid processing. J. Mater. Sci. 35, 5319-5329.

Tzimas, E., Zavaliangos, A., 2000b. Evolution of near-equiaxed microstructure in the semisolid state. Mater. Sci. Eng. A 289, 228-240.

Yong, K.P., Kyonka, C.P., Courtois, J.A., 1982. Fine grained metal composition. Patent. US 4415374. 